\title{
Caracterización y evaluación de la calidad de bentonitas provenientes de las provincias de San Juan y Río Negro (Argentina) para uso en industria petrolera y cerámica
}

\author{
Natalia Hidalgo, Ana Senese, Ester Cano y Pedro Sarquís \\ Universidad Nacional de San Juan, Facultad de Ingeniería, Av. Libertador 1109, (5400) San Juan, Argentina. \\ nhidalgo@unsj.edu.ar \\ asenese@unsj.edu.ar \\ estercano@unsj.edu.ar \\ psarquis@unsj.edu.ar
}

RESUMEN

El objetivo del presente trabajo es caracterizar física, química y mineralógicamente bentonitas provenientes de yacimientos de las provincias argentinas de San Juan y Rio Negro. El trabajo se completa con ensayos tecnológicos de evaluación de calidad de las muestras en estudio para determinar posibles usos y/o aplicaciones a nivel industrial.

Se trabajó con cuatro muestras de bentonitas identificadas como M1, M3, M4 provenientes de la provincia de San Juan y M2 de la provincia de Rio Negro. La caracterización física de las muestras consistió en la determinación de: hinchamiento, densidad, humedad, $\mathrm{pH}$ y peso específico mediante la aplicación de diferentes técnicas. La caracterización química de los componentes mayoritarios se realizó por métodos convencionales de vía húmeda (ataques ácidos). Mientras que los componentes minoritarios se analizaron mediante ICP. La caracterización mineralógica se realizó mediante el empleo de una espectrometría de infrarrojo. Los ensayos tecnológicos para la evaluación de calidad de las bentonitas se realizaron siguiendo la metodología indicada por las normas API y SEGEMAR, entre otras, para determinar posibles usos y/o aplicaciones principalmente en las industrias petrolera y cerámica.

Se concluye que la bentonita M2 es apta para uso en lodos de perforación por cumplir con los requerimientos especificados según normas API. Por otro lado por sus características físico-químicas y mineralógicas: baja reología, hinchamiento y bajo contenido en hierro, entre otros, la bentonita M3 es la que tiene mejores aptitudes para la industria cerámica.

Palabras clave: Argentina, bentonita, caracterización, yacimiento

\section{Quality characterization and evaluation of bentonites from the provinces of San Juan and Río Negro (Argentina) for their use in the oil and ceramics industries}

\author{
ABSTRACT
}

The aim of this research work is to characterize bentonites, both physically and chemically, as well as mineralogically, from deposits located in the Argentine provinces of San Juan and Rio Negro. The study is completed with technological assays to evaluate the quality of the samples under study so as to determine possible industrial uses and/or applications for this material.

To carry out this work, four samples of bentonite, identified as M1, M3, and M4, from the province of San Juan, and another, identified as M2, from the province of Rio Negro were used. Physical characterization consisted of determining: swelling, density, moisture, $\mathrm{pH}$ and specific gravity of the bentonite samples through application of a number of techniques. Chemical characterization of major components was carried out by using wet methods through acid attack, whilst ICP was used to characterize minor components. 
Hidalgo, N., et al., 2016. Caracterización y evaluación de la calidad de bentonitas... Boletín Geológico y Minero, 127 (4): $791-806$

Mineralogical characterization was carried out by using an infrared spectrometer. The technological assays for evaluating the quality of the bentonite were carried out following the method indicated by the API and SEGEMAR standards, among others, in order to determine possible uses and/or applications, mainly in the oil and ceramics industries

It was found that the M2 bentonite is the most suitable to be used as a drilling mud as it meets the requirements specified by the API standards. The M3 bentonite, due to its physico-chemical characteristics such as low rheology, swelling, low iron content, amongst others, is the most suitable for the ceramics industry.

Keywords: Argentina, bentonite, characterization, deposits

\section{ABRIDGED ENGLISH VERSION}

\section{Introduction}

Industrial minerals, among which clays are included, represent an important production in the world economy, with a relatively constant growth (from 40 to 50 billion tons) having been recorded between the years 1980 and 2002 (Behrens et al., 2007). The world production of clays with industrial uses has been estimated to be more than 100 million annual tons (Camacho and Celada, 2004). According to the U.S. Geological Survey, 2015, the world bentonite production and mine reserves are 12200 million tons. Argentina exports bentonite to more than a dozen countries, both neighbouring countries such as Brazil, Chile, Bolivia, Uruguay, Paraguay and others in South America (Peru, Venezuela and Colombia, amongst others). The lists of Argentine provinces devoted to the extractive and industrial activity are: Rio Negro, La Pampa, San Juan, Neuquen and Mendoza (UNSAM, 2007).

Ross and Shannon (1926) have defined bentonite as a rock that is mainly composed of crystaline clays formed by devitrification and chemical alteration accompanying vitreous igneous material, usually tuff or volcanic ash, with varying quantities of ancillary crystals that were formerly phenocrystals. The latter are feldspats (orthose and oligoclase), biotite, quartz, pyroxenes, zircons, etc. At present, the most widely accepted definition for bentonite is that of Grim, R. (1962): "Bentonite is a clay mainly composed of minerals from the smectite group, independently of its origin and mode of occurrence". From this standpoint, bentonite is a rock composed of more than one type of mineral, even though its essential constituents are smectites, which confer it its distinctive features.

Bentonite deposits from the province of San Juan, Argentine Republic, are located in two main districts: the western slope of the Sierra del Tontal (Tontal Low Mountain), between the districts of Colon to the north and Barreal to the south in the Department of Calingasta and the low mountains known as "Los Morados de Talacasto" (Talacasto Purple Mountains) in the Department of Jáchal. From the logistical standpoint, both districts present very good conditions for the development of the mining activity. Bentonite deposits are generated by the sedimentation of tuffs and volcanic ash which undergo further alteration by atmospheric agents. Thus, in a region with sedimentary accumulation, they are incorporated into the sedimentary sequence as one or several strata of this mineral. Later on, tectonism and weathering made these banks appear in a sedimentary sequence folded in weathered anticlines and sinclines.

The Calingasta Department deposits, from which the samples for this study were taken, is located in the Triasic basin that appears on the west flank of the Occidental Range, on the right bank of the Los Patos river, from the district of Colon to Barreal. The Triasic comprises the Barreal, Rincon Blanco and Mudadero Facies. These bentonite deposits are hosted in the Barreal group that extends on a wide and homogeneous strip of land to the East of Colon, Hilario, Sorocayense and Barreal (Shalamuk and Cabaña., 1999). They are $660 \mathrm{~m}$. thick and are made up of the Cepeda formation (250 m.); Cortaderita (200 m.) and Barreal (210 m.), see Figure 1.

In the Rio Negro valley, between General Roca and Pellegrini Lake, in the Department of General Roca, bentonite bearing horizons appear that are regularly mined (see Fig. 2). The Rio Negro bentonites, formed by montmorillonite and, less frequently, by beidellite and illite are produced by devitrification and chemical alteration of igneous vitreous material deposited in the coastal basins of scanty, low energy waters, partially restricted by the action of surges. The beginning and end of the abrupt sedimentation which gave rise to the bentonites might be accounted for by a short-lived pyroclastic event. According to Iñiguez et al. (1972), the three exploitable horizons located on the member of the Allen Formation have a potential of the order of 0.30 to 0.70 metres. The bentonite deposits from the department of General Roca are distributed in three areas: Lago Pellegrini (Pellegrini Lake), b) the northern area of Allen and General Roca and c) in the area of the Rio Colorado (Colorado River).

Bentonite is rarely used as a raw material; however, processing may be carried out to modify its properties so as to use it in specific industrial applications (Morgan et al., 1993). In general, characterization of clays 
Hidalgo, N., et al., 2016. Caracterización y evaluación de la calidad de bentonitas... Boletín Geológico y Minero, 127 (4): $791-806$

and bentonites in particular is carried out by determining their physical, chemical and mineralogical properties (Viruel and Lombardero, 1998). Quality evaluation of bentonites is made by means of specific industrial application tests according to suitable standards that obey consumer market specifications.

There are a number of industrial applications for clays nowadays, depending on their specific properties (Doval el at., 1991; Gonzales, 1990). Bentonite presents unique properties, making them highly valuable for various applications, such as drilling mudslides, ceramics, paints, adhesives, waterproofing and moulding sands for smelting works (Molina et al., 2007). The new refining methods and treatments have led this mineral to play an important role in areas such as agriculture and environmental protection, as well as in other applications. Its industrial use is based on its rheological and adsorption properties (Teague, 1972).

This study consists of the characterization of bentonite from the Argentine provinces of San Juan and Rio Negro by determining their physical, mineralogical and chemical properties. The study is completed with quality evaluation technological assays carried out in line with the methods indicated by the API and SEGEMAR standards, among others, in order to determine possible uses and/or applications.

\section{Methods}

To carry out the study, four samples of bentonite were used and identified as M1, M3, M4, these three from the province of San Juan, and a fourth, identified as M2, from Rio Negro. The samples were reduced to a -140 \# (ASTM) grain size, and were first subjected to physical characterization testing (Table 1), then, to chemical characterization testing (Tables 2) and finally to a mineralogical characterization carried out with a Terraspec 4 Hi-Res infra-red spectrometer (Table 3). The study was completed with technological testing for further quality assessment of the bentonites under study. In order to determine the value of bentonite as a drilling mud, the testings were conducted in compliance with the API standards (Table 2). For its use in ceramics, various physical assays were carried out that are detailed in Table 5.

\section{Results and discussion}

Once the various characterizations of the bentonite samples were finalized, the results of the specific assays conducted to determine possible uses and/or applications at an industrial level were evaluated. It was found that M2 bentonite is suitable to be used as a drilling mud as it complies with all the requirements specified by the API standards, as shown in Table 4. M3 bentonite is the most suitable for the ceramics industry (Table 5) due to its physicochemical and mineralogical characteristics, such as low rheology, swelling degree lower than $15(\mathrm{ml} / 2 \mathrm{~g})$ and low iron content, amongst others.

As regards the $M 1$ and $M 4$ bentonites, they present appropriate swelling properties and acceptable levels of heavy metals which would make them suitable to be used in other industries, such as those of animal nutrition and filtration.

\section{Introducción}

Los minerales industriales, entre los que se incluyen las arcillas, representan un renglón productivo importante en la economía mundial, registrando un crecimiento relativamente constante (de 40 a 55 billones de toneladas) entre los años 1980 y 2002 (Behrens et al., 2007). Según Camacho and Celada, 2004, la producción mundial de arcillas con fines industriales se estima en más de 100 millones de toneladas anuales. Según U.S. Geological Survey (2015), la producción y reservas de minas de bentonita a nivel mundial es de 12.200 millones de toneladas. Mientras que la producción de bentonita en Argentina durante el año 2013 fue de 200.000 toneladas (British Geological Survey, 2009-2013). La Republica Argentina exporta bentonita a más de una docena de países, tanto vecinos (Brasil, Chile, Bolivia, Uruguay, Paraguay) como otros de América (Perú, Venezuela, Colombia entre otros). La nómina de provincias argentinas productoras dedicadas a la actividad extractiva e industrial, son: Rio Negro, La Pampa, San Juan, Neuquén y Mendoza (UNSAM, 2007). La Provincia de San Juan posee una importante variedad de recursos de este tipo, algunos de los cuales representan importantes fuentes de materias primas para un amplio espectro de industrias (especialmente del cemento) y aporta una gran parte de la producción nacional de materiales calcáreos, bentonitas y travertino (Fundación Okita, 2007).

De acuerdo a Ross and Shannon (1926), definieron a la bentonita como una roca compuesta esencialmente de arcillas cristalinas formadas por la desvitrificación y alteración química acompañante del 
Hidalgo, N., et al., 2016. Caracterización y evaluación de la calidad de bentonitas... Boletín Geológico y Minero, 127 (4): $791-806$

material ígneo vítreo usualmente una toba o ceniza volcánica con cantidades variables de cristales accesorios que fueron originalmente fenocristales. Estos últimos son feldespatos (ortosa u oligoclasa), biotita, cuarzo, piroxenos, circones, etc. Actualmente la definición más aceptada para la bentonita es la dada por Grim, R (1962): “Bentonita es una arcilla compuesta esencialmente por minerales del grupo de las esmectitas, con independencia de su génesis y modo de aparición". Desde este punto de vista la bentonita es una roca compuesta por más de un tipo de minerales, aunque son las esmectitas sus constituyentes esenciales y las que le confieren sus propiedades características. El grupo de la esmectitas puede dividirse a su vez en dos subgrupos, las esmectitas dioctaédricas y las esmectitas trioctaédricas. Los criterios de clasificación utilizados por la industria se basan en su comportamiento y sus propiedades físico-químicas. La clasificación industrial más aceptada establece tipos de bentonitas en función de su capacidad de hinchamiento en agua. Según este criterio Patterson y Murray (1983) distinguen tres tipos principales: bentonitas altamente hinchables o sódicas; bentonitas poco hinchables o cálcicas y bentonitas moderadamente hinchables o intermedias. Posteriormente Odom (1984), siguiendo los mismos criterios de clasificación las divide en: bentonitas sódicas, bentonitas cálcico-magnésicas y Tierras de Fuller o tierras ácidas.

Los yacimientos bentoníticos de la provincia de San Juan República Argentina, se localizan en dos distritos principales: la falda occidental de la Sierra del Tontal, entre las localidades de Colón al norte y Barreal al Sur en el Departamento Calingasta y las serranías conocidas como Los Morados de Talacasto en el Departamento de Jáchal. Ambos distritos reúnen, desde el punto de vista logístico, muy buenas condiciones para el desarrollo de la actividad minera. Los yacimientos de bentonita se originan por la sedimentación de tobas y cenizas volcánicas que sufren una posterior alteración por los agentes atmosféricos. De este modo, en una región de acumulación de sedimentos quedan incorporados en la secuencia sedimentaria como uno o varios estratos de este mineral. Posteriormente, el tectónica y la erosión hacen aflorar estos bancos en una secuencia sedimentaria plegada en anticlinales y sinclinales erosionados.

Los yacimientos del departamento de Calingasta se encuentran localizados en la cuenca Triásica que aflora en el flanco occidental de la Cordillera Occidental, en el margen derecha del río de los Patos, desde la localidad de Colon hasta Barreal. Él Triásico comprende las Facies Barreal, Rincón Blanco y Mudadero. Estos yacimientos de bentonitas están alojados en el grupo Barreal que se extienden en una ancha y homogénea faja al este de Colón, Hilario, Sorocayense y Barreal (Shalamuk and Cabaña., 1999). Tiene un espesor de $660 \mathrm{~m}$. y está integrada por la formación Cepeda (250 m.), Cortaderita (200 m.) y Barreal $(210 \mathrm{~m})$, ver Figura 1.

Los niveles bentoníticos están localizados en la porción basal de la Fm. La Cortaderita y en toda la extensión de la Fm. Barreal. La litología está representada por alternancias de areniscas rojizas, amarillentas y grisáceas, conglomerados finos, lenticulares, limos tobáceos, grises, verdosos, arcillas limosas, carbonosas y bentonitas. Guerstein (1982) definió el grupo Sorocayense integrado por las formaciones El Alcázar, Hilario, Monina y Agua de los Pajaritos para el sector comprendido en Colón, Hilario y Sorocayense. Los mantos bentoníticos están localizados en la denominada Fm. Alcázar, en sus dos miembros superiores.

La serie volcaniclástica Triásica se depositó durante la etapa de extensión del Permo - Triásico, entre los ciclos orogénicos Gondwánico y Ándico. Esta serie conforma pliegues anticlinales y sinclinales con bordes de fallas al este y al oeste. La orientación general de las sedimentitas y los ejes de los pliegues es $\mathrm{N}-\mathrm{S}$. Los buzamientos de las capas varían de $40^{\circ}-60^{\circ}$ tanto al este como al oeste a horizontales. Los depósitos se localizan en capas con buzamiento de más de $30^{\circ}$ y asociados a estructuras anticlinales y fallas inversas (bordes de la cuenca).

En el caso de las bentonitas incluídas en el grupo Sorocayense, se trata de rocas estratificadas, que se han formado a partir de materiales volcánicos que previamente a su depositación han sufrido un largo transporte en el aire y luego han pasado por un estado intermedio donde fueron tobas y chonitas. El análisis geológico de las rocas del Grupo Sorocayense revela un ambiente de sedimentación occidental, así en las rocas del miembro Tobas Varicolores de la formación El Alcázar es posible distinguir dos grupos genéticos, uno formado por sedimentitas epiclásticas, en sus distintas facies de ambiente fluvial (oxidante): conglomerados, areniscas y pelitas rojas; el otro formado por sedimentitas piroclásticas y mixtas: tobas, bentonitas y tufitas que presentan caracteres de depósitos bajo el agua, posiblemente en lagunas de agua salada (contiene cristales de

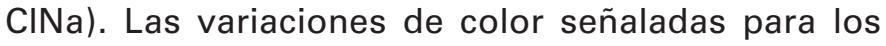
mantos de bentonita se relacionan con variaciones de las condiciones de $\mathrm{Eh}$ y $\mathrm{pH}$ del ambiente de sedimentación. Es probable que las bentonitas oscuras se hayan originado por contaminación con materia orgánica finamente dispersa en sectores litorales de la cuenca y bajo condiciones alcalinas. 
Las bentonitas amarillo verdoso y blancas se originaron en sectores de $\mathrm{pH}$ ligeramente ácido, insuficientes para producir la dispersión de la materia orgánica, bajo condiciones oxidantes en el primer caso y reductora en el segundo. Las sedimentitas piroclásticas representan depósitos en períodos de relativa estabilidad en el ambiente de sedimentación y por ende de escasos aportes piroclásticos. En estas condiciones los procesos de edafización podrían ser responsables de los cambios físico-químicos señalados y de la escasa estratificación de los bancos que infrayacen a la bentonita. La alteración o transformación de las chonitas a bentonitas, habría sido en este caso posterior a la sedimentación y controlada por la granulometría de las cenizas madres.

En general en todos los afloramientos se explotan cuatro mantos que tienen una extensión de 1 a $3 \mathrm{Km}$, la potencia promedio es de 1,7 m., el azimut de los bancos de bentonita es de $345^{\circ}$ y buzan $30^{\circ}$ al este.
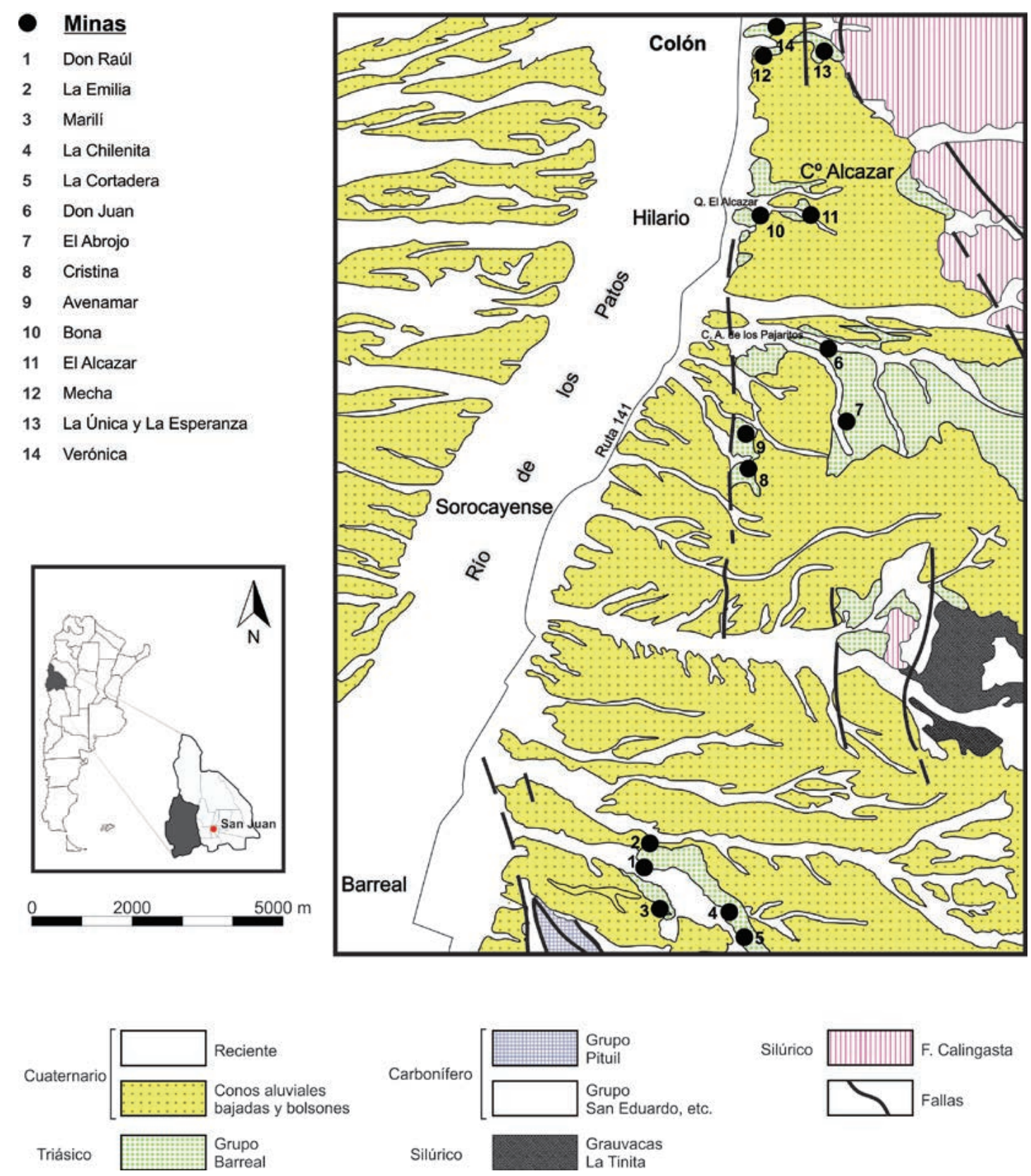

Silúrico

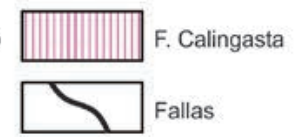

Figura 1. Geología de la región bentonítica Barreal-Hilario.

Figure 1. Geology of the Barreal-Hilario bentonite region. 
Según Wetten and Baraldo (1983), las reservas estimadas para la cuenca Sorocayense-Hilario y Colon, sitas en las provincia de San Juan son aproximadamente $8625000 \mathrm{t}$ de mineral, de la cual $2156250 \mathrm{t}$ (equivalente al $25 \%$ ) de bentonita de primera calidad (utilizadas en la industria de la alimentación y farmacéutica) y 6468750 t (75\%) corresponde a bentonitas de segunda calidad (usados para otras industrias: papel, caucho, pinturas, absorbentes, decolorantes, arenas de moldeo, etc.).

En el valle de Rio Negro, entre General Roca y el Lago Pellegrini, en el Departamento General Roca, afloran horizontes portadores de bentonitas que son explotados regularmente (ver Figura 2). Las bentonitas de Río Negro están formadas por montmorillonita y con menor frecuencia por beidellita e illita, son producto de desvitrificación y alteración química de material vítreo ígneas depositadas en cuencas litorales de aguas someras de baja energía, parcialmente restringido a la acción del oleaje. EI abrupto comienzo y fin de la sedimentación que dió origen a las bentonitas, podrían ser explicados por un acontecimiento piroclástico de corta duración. Según Iñiguez et al., 1972, los tres horizontes explotables ubicados en el miembro de la Formación Allen, tienen potencias del orden de los 0,30 a los 0,70 metros. Los depósitos de bentonitas del departamento General Roca están distribuidas en tres áreas:
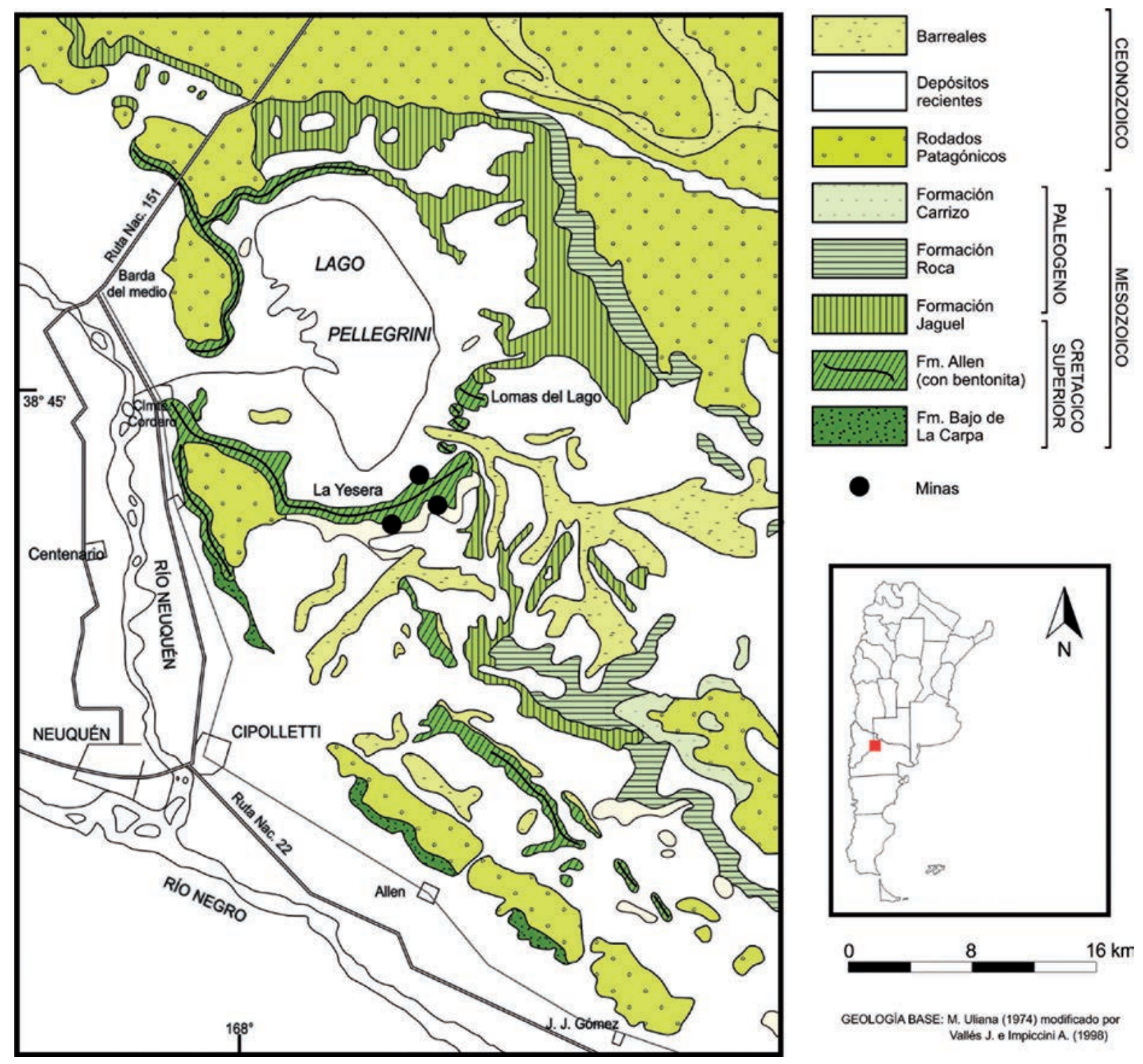

GEOLOGIA BASE: M. Uliana (1974) modificado por Vallés J. e Impiccini A. (1998)

Figura 2. Geología de los depósitos de bentonitas, área Río Negro-Río Neuquén.

Figure 2. Geology of deposits of bentonite, Neuquen River and Black River area. 
a) Lago Pellegrini, b) área norte del Allen y General Roca y c) área del Rio Colorado. La primera área es la más importante desde el punto de vista productivo. Aquí la bentonita se encuentra en la sección media de la Formación Allen, en bancos tabulares de gran extensión areal y hasta 0.70 metros de potencia, o en cuerpos lentiformes de menor espesor ( 0.15 metros), ambos inmersos en fangolitas que conforman un escape de 4 a 6 metros. La mineralización presenta color verde claro, verde oliva y gris blanquecino con manchas de óxido de hierro (Valles and Impiccini, 1999).Las principales minas son La Angelita, Ducodo y Enrique. Las bentonitas del Lago Pellegrini tienen como componente principal la montmorillonita (esmectita dioctaédrica) y como componentes acompañantes feldespatos (oligoclasa-andesita), cuarzo, clastos líticos, trizas de vidrio y zeolitas.

Como consecuencia de las perspectivas crecientes del consumo y debido al desarrollo de nuevas aplicaciones, el mercado de bentonitas se diversifica y se amplía en los mercados nacionales e internacionales, gracias a que se encuentra ampliamente distribuida a nivel mundial.

La bentonita es raramente usada en la forma de material en bruto, pero mediante procesamiento se modifican sus propiedades para su utilización en aplicaciones industriales especificas (Morgan et al. 1993). En general, la caracterización de las arcillas y de las bentonitas en particular se efectúa mediante determinaciones de propiedades físicas, químicas y mineralógicas (Viruel and Lombardero, 1998). La evaluación de la calidad de las bentonitas se realiza mediante ensayos específicos de aplicación industrial de acuerdo a las normas adecuadas que obedecen a las especificaciones del mercado consumidor.

En la actualidad las arcillas son usadas en numerosas aplicaciones industriales, dependiendo de sus propiedades específicas (Doval el at., 1991; Gonzales, 1990). La bentonita tiene propiedades únicas en diversas aplicaciones que la hacen muy valiosas, tales como: lodos de perforación, cerámicas, pinturas, peletización, alimentos balanceados, cosmética, pinturas, adhesivos, impermeabilización y arenas de moldeo para fundiciones (Molina et al., 2007). Los nuevos métodos y tratamientos de refinamientos han Ilevado a este mineral a desempeñar un papel importante en áreas como la agricultura o protección ambiental y en otras aplicaciones. Su uso industrial está basado en sus propiedades reológicas y de adsorción (Teague, 1972).

En este contexto, el presente trabajo consiste en la caracterización de bentonitas procedentes de las provincias argentinas de San Juan y Río Negro mediante la determinación de sus propiedades físicas, químicas y mineralógicas. El trabajo se completa con ensayos tecnológicos de evaluación de calidad, siguiendo la metodología indicada por las normas API y SEGEMAR, entre otras, para determinar posibles usos y/o aplicaciones.

\section{Materiales y métodos}

Se trabajó con cuatro muestras de bentonitas identificadas como M1, M3, M4 provenientes de la provincia de San Juan (Grupo Barreal) y M2 de la provincia de Rio Negro (Lago Pellegrini).

Las muestras se redujeron a una granulometría de -140 \# (ASTM) en tamizadora vibratoria equipo Zonytest Standart EJR modelo LR 2006, a las cuales se le realizaron ensayos de caracterización físico-química y mineralógicos acompañados por ensayos tecnológicos para posterior evaluación de la calidad de las bentonitas en estudio.

\section{Ensayos de caracterización}

\section{A- Propiedades Físicas:}

1. Determinación hinchamiento: según norma IRAM 165311:2001, se expresa el hinchamiento como el volumen alcanzado por el contenido de una probeta, después de 24 horas de haber finalizado el agregado de bentonita seca, en mililitros. Se tomó 2 gramos de bentonita previamente tamizada a 200 mallas y secada en estufa $\left(105^{\circ} \mathrm{C}\right)$, luego se espolvorea suave y lentamente sobre 100 mililitros de agua en una probeta, evitando que el sólido toque las paredes y esperando que todo haya sedimentado antes de hacer otro agregado. Se dejó reposar 24 horas y por último se leyó el volumen de solidos alcanzado.

2. Humedad: se realizó en estufa a $105^{\circ} \mathrm{C}$ hasta peso constante según apartado 3.6 normas API $13 \mathrm{~A}$.

3. Densidad: se prepararon suspensiones al $6 \%$, agitado en un multimixer durante 20 minutos y luego se midieron sus densidades a través de balanza de lodos Marca Fann según normas API. La balanza de lodo es un dispositivo de medición preciso utilizado para determinar la densidad del fluido de perforación. Consiste en una copa donde se coloca las muestras a un volumen constante, la cual se conecta a un brazo de equilibrio que tiene cuatro escalas graduadas. Un jinete se mueve a lo largo del brazo de la balanza para indicar las lecturas de la escala.

4. Lectura de $\mathrm{pH}$ : las suspensiones preparadas al $6 \%$, se midieron en un microprocesador Fisher modelo Accumet 50 según Normas API sección II. 
Hidalgo, N., et al., 2016. Caracterización y evaluación de la calidad de bentonitas... Boletín Geológico y Minero, 127 (4): $791-806$

5. Peso Específico: según especificaciones API 13AMétodo del frasco Le Chatelier. Para ello se Ilenó un frasco de Le Chatelier con keroseno (liquido orgánico de baja volatilidad) hasta un punto entre 0 y 1 mililitros asegurándose de que quede seco en el interior por encima de este nivel, esta lectura fue el volumen inicial. Luego se agregó 60 gramos de bentonita, la cual ha sido previamente secada durante un mínimo de 2 horas a $105^{\circ} \mathrm{C}$, teniendo cuidado de no derramar el líquido ni untar las paredes por encima de este nivel, se determinó la lectura del volumen final después de haber colocado el frasco en un baño termostático a una temperatura aproximada de $10{ }^{\circ} \mathrm{C}$ por sobre temperatura ambiente. La diferencia entre el volumen final e inicial representa el volumen de líquido desplazado por el peso de la muestra usada.

\section{B- Propiedades Químicas:}

La caracterización química de los elementos mayoritarios se realizó por vía húmeda a través de ataques ácidos y posterior determinación por métodos analíticos de separación y calcinación o volumétria para los siguientes compuestos: $\mathrm{SiO}_{2}, \mathrm{Fe}_{2} \mathrm{O}_{3}, \mathrm{CaO}, \mathrm{MgO}$, $\mathrm{Al}_{2} \mathrm{O}_{3}$, ya que no se disponen de normas oficiales:

- Determinación del contenido de $\mathrm{SiO}_{2}$ : en un crisol de zirconio, se adicionan $0,5 \mathrm{~g}$ de bentonita seca y se añade 5 veces el peso de la muestra en carbonato de sodio $\left(\mathrm{Na}_{2} \mathrm{CO}_{3}\right)$. Se mezcla, se tapa y se lleva a fundición por 10 minutos a $855^{\circ} \mathrm{C}$. Esta determinación es realizada en una mufla thermo scientific termolyne ${ }^{\circledR} 120 \mathrm{~V}$. Transcurrido este tiempo, se enfría el crisol y se transfiere su contenido a un vaso de precipitados adicionando lentamente 20 $\mathrm{ml}$ de $\mathrm{HCl}$ 1:1 dejando evaporar cuidadosamente hasta sequedad. Luego se adicionan $5 \mathrm{ml}$ de $\mathrm{HCL}$ $1: 1$ y $50 \mathrm{ml}$ de agua destilada caliente. Se filtra y se lava con agua destilada caliente hasta que el precipitado esté libre de cloruros (se comprueba con una solución de nitrato de plata al $2 \%$ ). El precipitado se calcina a $800^{\circ} \mathrm{C}$ por espacio de una hora. El porcentaje de $\mathrm{SiO}_{2}$ se calcula mediante la siguiente ecuación (Lazo, 2006): \% $\mathrm{SiO}_{2}=($ Peso del calcinado $(\mathrm{g}) /$ Peso de la muestra) $* 100$.

- Determinación del contenido de $\mathrm{Al}_{2} \mathrm{O}_{3}$ y $\mathrm{F}_{2} \mathrm{O}_{3}$ : se toman $100 \mathrm{ml}$ de la solución resultante en la determinación de $\mathrm{SiO}_{2}$, se calienta y se agrega $5 \mathrm{ml}$ de $\mathrm{H}_{2} \mathrm{O}_{2}(50 \%), 10 \mathrm{ml}$ de $\mathrm{NH}_{4} \mathrm{OH}(30 \%)$ y $1 \mathrm{~g}$ de $\mathrm{NH}_{4} \mathrm{OH}$. Se calienta y se deja ebullir 5 minutos. Se retira del calor y se deja decantar el precipitado. Se filtra, se seca y se calcina a $1100^{\circ} \mathrm{C}$. El residuo se pesa como $\mathrm{R}_{2} \mathrm{O}_{3}$. El contenido de Fe se calcula como $\mathrm{Fe}_{2} \mathrm{O}_{3}$ aplicando el factor 1.4 y se resta al
$\mathrm{R}_{2} \mathrm{O}_{3}$. El porcentaje de $\mathrm{Al}_{2} \mathrm{O}_{3}=\% \mathrm{R}_{2} \mathrm{O}_{3}-\% \mathrm{Fe}_{2} \mathrm{O}_{3}$ (Lazo, 2006).

- Determinación CaO: el líquido proveniente de la marcha anterior se reduce de volumen por evaporación y luego se le agrega $10 \mathrm{ml}$ de $\mathrm{NH}_{3}$ (concentrado). Luego se tapa y siempre en caliente, se agrega oxalato de amonio, después se hierve 5 minutos dejando decantar, se filtra y por último se lava con agua. En el vaso original que estuvo ese precipitado se coloca $200 \mathrm{ml}$ de agua con 6 $\mathrm{ml}$ de $\mathrm{HCL}$, se calienta a $70^{\circ} \mathrm{C}$ y se agrega el papel de filtro que contiene el oxalato de calcio. Se titula con permanganato y multiplicando por 0.5021 ésta nos da el porcentaje de $\mathrm{CaO}$.

- Determinación de MgO: el líquido proveniente del ensayo anterior, se reduce de volumen y se enfría, luego se agrega $15 \mathrm{ml}$ de $\mathrm{NH}_{3}$ y $6 \mathrm{ml}$ de una solución saturada de fosfato de amonio. Se agita durante 15 minutos, dejando decantar para después filtrar, lavando el precipitado con una solución que contiene una parte de $\mathrm{NH}_{3}$ y otra de agua. Por último se calcina en crisol de platino tarado y se pesa.

La determinación de los elementos minoritarios tales como sodio, calcio y metales pesados, se realizaron por la técnica ICP (Plasma de Acoplamiento Inductivo) en el Laboratorio de Análisis Instrumental del Instituto de Investigaciones Mineras. La relación de $\mathrm{Na}_{2} \mathrm{O} / \mathrm{CaO}$ permite clasificar las bentonitas en sódicas o cálcicas.

\section{C- Mineralógicas:}

El estudio mineralógico llevado a cabo sobre las muestras en estudio, fue realizado mediante el empleo de un espectrómetro de infrarrojo Terraspec $4 \mathrm{Hi}-\mathrm{Res}$ (AusSpec International-ASD Inc.). La estimación cuantitativa de las distintas fases mineralógicas presentes en cada una de las muestras fue obtenida a partir del empleo del software TSG (The Spectral Geologist, versión 7.1.0.060. AusSpec International).

\section{Ensayos de Evaluación de las bentonitas para diferen- tes usos}

\section{D- Ensayos para uso en perforación:}

Para el control de la calidad del lodo es necesario conocer sus propiedades reológicas, principalmente la viscosidad, como así también el filtrado y la presencia de residuos. La técnica utilizada para la determinación de los ensayos es la indicada por la Norma API (Instituto Americano de Petróleo), los cuales se detallan a continuación: 
- Viscosidad: para ello se prepararon suspensiones de las muestras al $6 \%$ agitadas en un multimixer Hamilton Beach ${ }^{\circledR}$ y almacenadas aproximadamente 16 horas (tiempo de envejecimiento). Pasado ese tiempo se tomó la suspensión y se agitó durante 5 minutos y se determinó la viscosidad a velocidades de 300 y $600 \mathrm{rpm}$ en un viscosímetro Fann FS-35® tipo rotacional de lectura directa. La viscosidad plástica (V.P), en centipoise es igual a la diferencia entre las lecturas a 600 r.p.m y a 300 r.p.m.

- Punto de Fluencia: es igual a la lectura a 300 r.p.m menos la viscosidad plástica (V.P).

- Filtración: las características de filtración y de formación de revoque del lodo, se determinan por medio de un filtro prensa marca Ofite ${ }^{\circledR}$ (según Norma API 13A) con cartuchos de $\mathrm{CO}_{2}$, trabajando a una presión de 100 psi. Se registra los mililitros de filtrado pasado los treinta minutos y se determina el espesor de la torta formada para cada muestra. Se considera un parámetro importante a tener en cuenta, debido a que uno de los propósitos del uso de la bentonita es favorecer la retención de agua y la pérdida de fluido de circulación.

- Impurezas \# 200: este ensayo se realizó según Norma API 13A, se pesó 10 gramos de bentonita y luego se agregó a 350 mililitros de agua conteniendo 0.2 gramos de fosfato sódico, agitando durante media hora y luego dejando decantar durante un mínimo de 2 horas. A continuación, se vierte la muestra en un tamiz malla 200 (75 micrones) lavando continuamente durante 10 minutos., transfiriéndose el residuo del tamiz a una cápsula. Por último se determina el porcentaje en peso de las partículas que quedaron retenidas sobre el tamiz.

- Humedad: se pesó 10 gramos de bentonita, luego se secó a peso constante a una temperatura de $105^{\circ} \mathrm{C}$ (Ídem al ensayo descripto en la caracterización física).

\section{E- Ensayos para uso en cerámica}

Una de las primeras aplicaciones de las arcillas fue en cerámica, para preparar pastas aprovechando su propiedad plástica que mejora la resistencia y actúa como agente aglutinante. La bentonita no se usa en grandes volúmenes justamente por su plasticidad, se adiciona para aumentar y dar la vitrificación apropiada o el color deseado. Para la evaluación de las bentonitas para su uso en cerámica se efectúo determinando las siguientes propiedades:

- Propiedades físicas y químicas:

- Hinchamiento: según Norma IRAM 165311:2001(valor ya calculado en el ensayo descrito de la caracterización física).
- $\mathrm{Fe}_{2} \mathrm{O}_{3}$ : calculado en el ensayo descripto en la caracterización química.

- Densidad: mediante lectura en balanza de lodos tipo Fann ${ }^{\circledR}$ (valor ya calculado en el ensayo descripto en la caracterización física).

- Blancura: mediante un reflectómetro Photovolt ${ }^{\circledR}$ Modelo 610 equipado con placas esmeriladas con valores de reflexión de 70-75 $\%$ que se lee con filtros de vidrio azul, verde $y$ amarillo. La medición con el filtro azul indica la reflectancia o blancura de la bentonita. La técnica usada para esta determinación es la indicada por la Norma ECC P110 E.

- Índice de Plasticidad: según Norma IRAM 10501.El índice de plasticidad (IP) de un suelo es la diferencia numérica entre los valores del límite líquido (LL) y el límite plástico (LP) de un mismo suelo. Es decir IP = LL - LP. Donde el límite líquido, se define como el contenido de humedad necesario para que las dos mitades de un pasta de bentonita fluya y se unan en una longitud de $12 \mathrm{~mm}$, en el fondo de la muesca que separa las dos mitades, cuando la cápsula que la contiene golpea entre 25 y 30 veces desde un altura de $100 \mathrm{~mm}$, a la velocidad de 2 golpes por segundo. Mientras que el limite plástico se define como el más bajo contenido de humedad con la cual la pasta, al ser moldeada en barritas cilíndricas, comienza a agrietarse cuando las barritas alcanzan a tener $3 \mathrm{~mm}$ de diámetro.

\section{Resultados y discusión}

\section{A-Caracterización Física.}

Los resultados obtenidos de las muestras en estudio se detallan en Tabla 1:

\begin{tabular}{|l|c|c|c|c|}
\hline $\begin{array}{l}\text { Determinaciones } \\
\text { Físicas }\end{array}$ & $\begin{array}{c}\text { Bentonita } \\
\text { M1 }\end{array}$ & $\begin{array}{c}\text { Bentonita } \\
\text { M2 }\end{array}$ & $\begin{array}{c}\text { Bentonita } \\
\text { M3 }\end{array}$ & $\begin{array}{c}\text { Bentonita } \\
\text { M4 }\end{array}$ \\
\hline $\begin{array}{l}\text { Hinchamiento } \\
\text { (ml/2 g) }\end{array}$ & 20 & 40 & 10 & 20 \\
\hline Humedad (\%) & 7.90 & 8.90 & 4.78 & 4.60 \\
\hline $\begin{array}{l}\text { Densidad } \\
\left.\text { (g/cm }{ }^{3}\right)\end{array}$ & 1.04 & 1.05 & 1.03 & 1.06 \\
\hline pH & 8.1 & 8.0 & 8.2 & 8.1 \\
\hline $\begin{array}{l}\text { Peso Específico } \\
\left(\mathrm{g} / \mathrm{cm}^{3}\right)\end{array}$ & 2.36 & 2.34 & 2.27 & 2.49 \\
\hline
\end{tabular}

Tabla 1: Resultados obtenidos de la caracterización física de las muestras de bentonitas.

Table 1. Results obtained from the physical characterization of the bentonite samples. 
Hidalgo, N., et al., 2016. Caracterización y evaluación de la calidad de bentonitas... Boletín Geológico y Minero, 127 (4): $791-806$

Podemos observar a partir de los resultados de esta caracterización que:

La muestra de bentonita M2 posee un alto hinchamiento en relación a las otras muestras estudiadas. De acuerdo a Laird, 2006, el hinchamiento de una esmectita es un fenómeno complejo. La absorción de agua en el espacio interlaminar tiene como consecuencia la separación de las láminas dando lugar al hinchamiento. Este proceso depende del balance entre la atracción electrostática catión-lámina y la energía de hidratación del catión. Cuando el catión interlaminar es el sodio, las esmectitas tienen una gran capacidad de hinchamiento, y si por el contrario tienen calcio o magnesio como cationes de cambio su capacidad de hinchamiento será mucho más reducida. Para que una arcilla pueda ser considerada como bentonita, en el sentido comercial de la palabra, debe hincharse aumentando por lo menos cinco veces su volumen. Normalmente una bentonita de buena calidad se hincha en agua de 10 a 20 veces su volumen; en casos excepcionales esta relación llega a 30 (Herbia, 2007).

Todas las muestras tienen un porcentaje de humedad permitido menor al $10 \%$, cumpliendo con lo especificado según normas API. Esto se condice con que la humedad de las bentonitas provenientes de la explotación oscila entre 9 y $15 \%$. Valores inferiores a $6 \%$ de humedad no son convenientes por razones económicas, ya que necesita mayor consumo de energía para el secado y problemas de re-hidratación.
La densidad puede expresarse en distintas unidades, entre ellas Kilopascales por metro por 100 metros de lodo en el pozo, esta última medida es la más conveniente para calcular la altura hidrostática de la columna del lodo bentonítico usado en perforaciones para cualquier profundidad del pozo, porque esta expresada en las mismas unidades empleadas para la presión de la bomba y para la presión del fluido de formación. La densidad debe mantenerse dentro de ciertos límites (1.10 - $\left.1.22 \mathrm{~g} / \mathrm{cm}^{3}\right)$, es decir, lo suficientemente alta para impedir cabeceos, y lo suficientemente baja para evitar las pérdidas de circulación y también para mejorar el régimen de penetración (Peña, 2007).

El pH de la suspensión de una arcilla puede dar una indicación de la presencia de álcalis en la misma. Para el caso de las bentonitas usadas como viscosificantes en los lodos de perforación para mejorar el rendimiento del lodo, deben mantenerse en cierto grado de alcalinidad, en un rango de $\mathrm{pH}$ entre 8 a 9.5 (Arredondo, 2009). Según Marconi, 1998, las bentonitas pertenecientes a Lago Pellegrini tienen normalmente $\mathrm{pH}$ neutro o levemente ácido, mientras que las bentonitas de San Juan tienen $\mathrm{pH}$ que varían entre 7 a 9. Las lecturas de valores de $\mathrm{pH}$ de las muestras en estudio resultaron ligeramente alcalinas variando entre 8 y 9 dependiendo de la zona geográfica del yacimiento a las que pertenecen.

Los valores de peso específico obtenidos de las muestras estudiadas comparadas con los valores

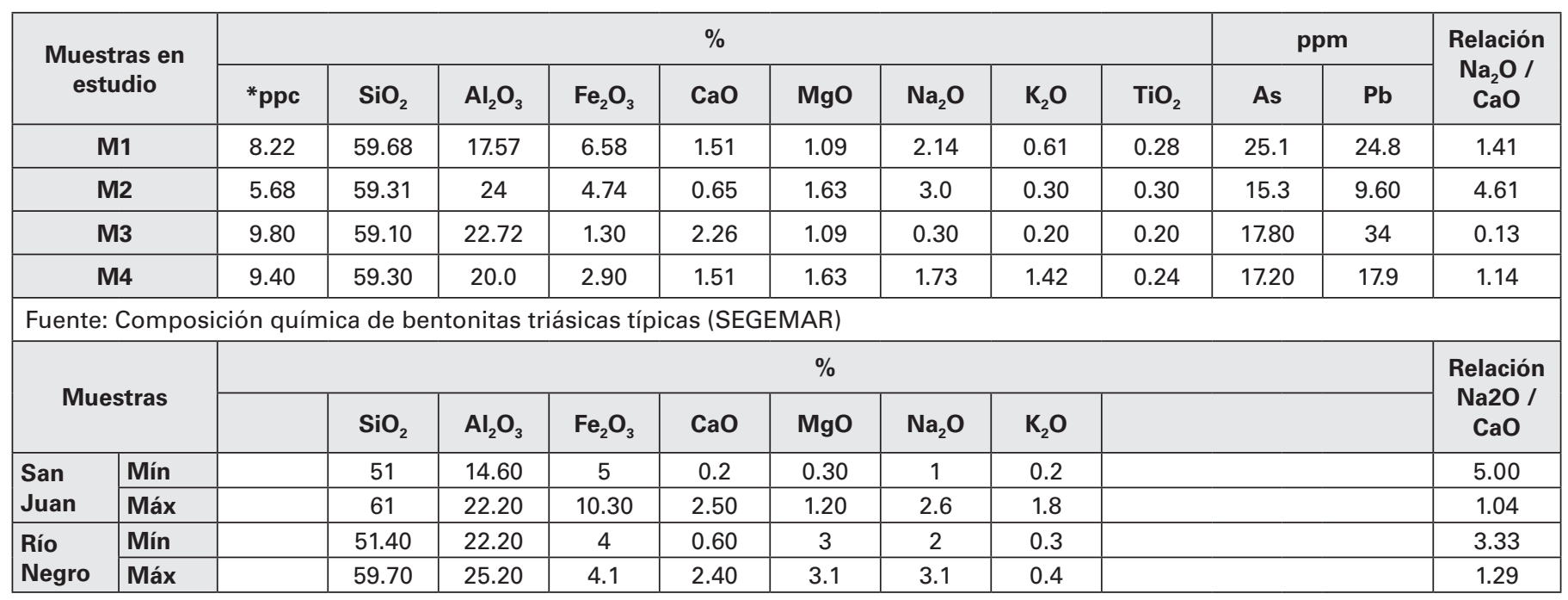

* ppc $=$ pérdidas por calcinación.

Tabla 2. Resultados obtenidos de la caracterización química de las muestras de bentonitas, junto con la composición química de bentonitas triásicas pertenecientes a las provincias de San Juan y Rio Negro.

Table 2. Results obtained from the chemical characterization of the bentonite samples along with chemical composition of triassic bentonites from the provinces of San Juan and Rio Negro. 
habituales para este tipo de arcillas son adecuados variando entre 2.2 a $2.8 \mathrm{~g} / \mathrm{cm}^{3}$.

\section{B-Caracterización Química.}

En Tabla 2 se observan tanto los resultados de la caracterización química de las muestras de bentonitas en estudio, como así también la composición química típica de los componentes mayoritarios de las bentonitas triásicas de las provincias de San Juan y Rio Negro (SEGEMAR).

En función de analizar los resultados de las bentonitas en estudio se observa que el elemento predominante es el sodio siendo mayores para las muestras M2, M1, M4. Esto condice con que la capacidad de hinchamiento de las bentonitas depende de la naturaleza del catión intercambiable y de la carga laminar. Cuando el catión interlaminar es el sodio, las bentonitas tienen una gran capacidad de hinchamiento, pudiendo llegar a producirse la completa disociación de cristales individuales, obteniendo como resultado un alto grado de dispersión y un máximo desarrollo de propiedades coloidales (Hebia, 2007). Por lo tanto la bentonita M2 posee un hinchamiento más elevado en comparación con las otras muestras, presentado además una relación $\mathrm{Na}_{2} \mathrm{O} / \mathrm{CaO}$ mayor.

Para el caso de la bentonita M3 predomina el elemento calcio, desarrollando el valor más bajo de hinchamiento (ver Tabla 1). Esto se debe a que, cuando el catión interlaminar predominante es el $\mathrm{Ca}$, la capacidad de hinchamiento es mucho más reducida, ya que este ión ayuda a la formación de una estructura rígida de las primeras capas de agua adsorbidas, pero al adsorber capas adicionales, estos iones promueven desorden y las capas de agua pierden rápidamente su estructura rígida (Odom, 1987). Con respecto a la composición química de las muestras
M1, M3 y M4 (San Juan) se obtienen valores promedios de: $59 \%$ de $\mathrm{SiO}_{2} ; 21 \%$ de $\mathrm{Al}_{2} \mathrm{O}_{3} ; 3.9 \%$ de $\mathrm{Fe}_{2} \mathrm{O}_{3}$; $1.5 \%$ de $\mathrm{CaO} ; 1.8 \%$ de $\mathrm{Na}_{2} \mathrm{O} ; 1.4 \%$ de $\mathrm{MgO} ; 0.6 \%$ de $\mathrm{K}_{2} \mathrm{O}$, ajustándose de esta manera a la composición química de bentonitas típicas (SEGEMAR) detalladas en Tabla 2.Siendo la principal característica química de estas bentonitas de San Juan, su bajo contenido de hierro.

La composición química de la bentonita M2 (Lago Pellegrini), se ajusta también a los valores típicos de bentonitas dados por SEGEMAR.

\section{C- Caracterización mineralógica.}

Los resultados de los espectros obtenidos en cada una de las muestras analizadas se detallan en la Figuras 3, 4, 5 y 6 . Dichos espectros tienen el aspecto característico de los correspondientes a los distintos minerales arcillosos (Dias et al., 2004; Madejová and Komadel, 2001). La Tabla 3 muestra las especies mineralógicas presentes de las muestras de bentonitas.

Los depósitos de bentonita están compuestos principalmente por las especies minerales del grupo de las esmectitas y son estos minerales lo que le dan al material bentonítico sus propiedades fisicoquímicas únicas. Existen otros minerales encontrados en bentonitas que frecuentemente pueden hallarse dentro de las siguientes categorías: a) de origen volcánico (feldespatos, biotita, cuarzo, cristobalita, apatita, etc.); b) mineral secundario (feldespatos calco-sódicos); c) aquellos que son contaminantes detríticos tal como el cuarzo (Vega et al., 1993). Según Grim, 1978 , define a la bentonita como una arcilla constituida principalmente (en general, más del $65 \%$ ) por un mineral perteneciente a la familia de las esmectitas: la montmorillonita, asumiéndose las propiedades de la bentonita como las propiedades del mineral.

\begin{tabular}{|c|c|c|c|c|c|}
\hline Composición mineralógica & Nombre & M1(\%) & M2(\%) & M3(\%) & M4(\%) \\
\hline$(\mathrm{Ca}, \mathrm{Na})_{0.3}(\mathrm{Al}, \mathrm{Mg})_{2} \mathrm{Si}_{4} \mathrm{O}_{10}(\mathrm{OH})_{2} \cdot \mathrm{nH}_{2} \mathrm{O}$ & Montmorillonita & 72 & 91 & 69 & 72 \\
\hline $\mathrm{KAI}_{2}(\mathrm{OH}, \mathrm{F}) \mathrm{AISi}_{3} \mathrm{O}_{10}$ & Muscovita & 21 & - & 24 & - \\
\hline $\mathrm{Ca}_{0.25}(\mathrm{Mg}, \mathrm{Fe})_{3}\left((\mathrm{Si}, \mathrm{Al})_{4} \mathrm{O}_{10}\right)(\mathrm{OH})_{2 .} \mathrm{nH}_{2} \mathrm{O}$ & Saponita & 7 & -- & -- & -- \\
\hline $\mathrm{AlSi}_{3} \mathrm{O}_{10} \mathrm{~K}(\mathrm{Mg}, \mathrm{Fe})_{3}(\mathrm{OH})_{2}$ & Biotita & -- & -- & -- & 20 \\
\hline $\mathrm{Na}_{0.3} \mathrm{Fe}_{2}\left((\mathrm{Si}, \mathrm{Al})_{4} \mathrm{O}_{10}\right)(\mathrm{OH})_{2} \cdot \mathrm{nH}_{2} \mathrm{O}$ & Nontronita & -- & 9 & -- & 8 \\
\hline $\mathrm{CaSO}_{4} \cdot 2 \mathrm{H}_{2} \mathrm{O}$ & Yeso & -- & -- & -- & -- \\
\hline $\mathrm{Al}_{2}\left(\mathrm{Si}_{4} \mathrm{O}_{10}\right)(\mathrm{OH})_{2}$ & Pirofilita & -- & -- & 6 & -- \\
\hline
\end{tabular}

Tabla 3. Resultados de la caracterización mineralógica de las muestras.

Table 3. Results of the mineralogical characterization of samples. 

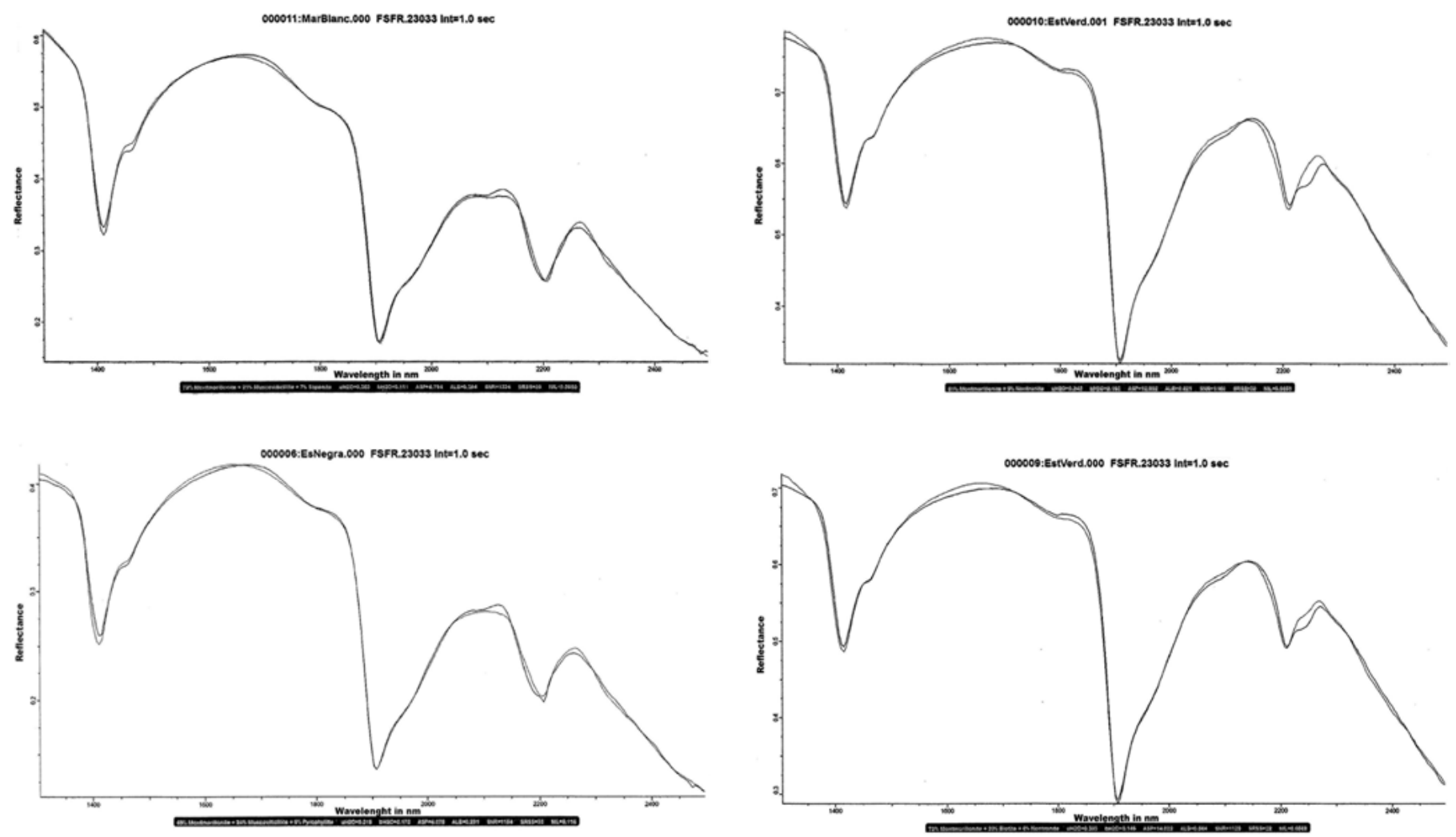

Figura 3. Espectros de las muestras M1 (superior derecha), M2 (superior izquierda), M3 (inferior derecha) y M4 (inferior izquierda). Figure 3. Spectra of samples M1 (top left), M2 (top right), M3 (bottom left) and M4 (bottom right).

Para el caso de la muestra M1 (Figura 3), la montmorillonita es la principal especie arcillosa predominante y en menor proporción la muscovita (perteneciente al grupo de los silicatos) y saponita.

La muestra M2 (Figura 4) presenta el mayor porcentaje de montmorillonita comparado con las demás muestras, junto con la presencia de nontronita. Esto se condice con que estos minerales pertenecen al grupo de las llamadas"esmectitas", cuyas características físicas son su capacidad de absorber agua (aumento de volumen), plasticidad, impermeabilidad y propiedades coloidales. Esto conlleva a que ésta bentonita presenta mayor expansión (hinchamiento) comparado con las demás.

Para el caso de la muestra M3 (Figura 5) presenta el menor contenido en montmorillonita, seguida de muscovita y pirofilita.

Para el caso de la muestra M4 (Figura 6) predomina como especie mineral la montmorillonita, acompañado por biotita (perteneciente al grupo de las micas) y nontronita (especie rica en hierro).

Resumiendo, la montmorillonita es la principal especie arcillosa predominante en todas las muestras estudiadas siendo esto coincidente con la propia definición de bentonita, confiriéndole en mayor o menor medida sus propiedades fisicoquímicas. Una vez finalizada las distintas caracterizaciones de las muestras de bentonitas, se procede a evaluar los resultados obtenidos de los ensayos específicos para determinar posibles usos y/o aplicaciones a nivel industrial.

Los resultados de los ensayos de evaluación de las bentonitas para diferentes usos se detallan a continuación:

\section{D- Ensayos para uso en perforación.}

A pesar de los importantes cambios que van sufriendo con el tiempo las formulaciones de los lodos de perforación, este sigue siendo uno de los mercados más importantes de las bentonitas. El $53 \%$ de la bentonita obtenida mundialmente es utilizada en la industria petrolera como aditivo en lodos de perforación. El objeto principal es aumentar la viscosidad del lodo, permitiendo mantener en suspensión y transportar efectivamente el "cutting" (restos de roca resultantes de la perforación) a la superficie (Roskill, 1997).

Para el control de la calidad del lodo es necesario conocer sus propiedades reológicas, principalmente 
Hidalgo, N., et al., 2016. Caracterización y evaluación de la calidad de bentonitas... Boletín Geológico y Minero, 127 (4): $791-806$

\begin{tabular}{|c|c|c|c|c|c|}
\hline \multirow{2}{*}{ Determinaciones } & \multicolumn{4}{|c|}{ Muestras en estudio } & \multirow{2}{*}{$\begin{array}{c}\text { Especificaciones físicas } \\
\text { de las Bentonitas } \\
\text { Normas API }\end{array}$} \\
\hline & M1 & M2 & M3 & M4 & \\
\hline $\begin{array}{l}\text { Viscosidad Fann, lectura del dial a } \\
600 \mathrm{rpm}\left(\mathrm{T}^{\circ}=27.6^{\circ} \mathrm{C}\right)\end{array}$ & $28 \mathrm{cP}$ & $49 \mathrm{cP}$ & $6 \mathrm{cP}$ & $24 c P$ & Mínimo 30 \\
\hline $\begin{array}{l}\text { Viscosidad Fann, lectura del dial a } \\
300 \mathrm{rpm}\left(\mathrm{T}^{\circ}=26.1^{\circ} \mathrm{C}\right)\end{array}$ & $22 \mathrm{cP}$ & $42 \mathrm{cP}$ & $4 \mathrm{cP}$ & $19 \mathrm{cP}$ & -- \\
\hline Punto de fluencia, lb/100 $\mathrm{pie}^{2}$ & 16 & 35 & 2 & 14 & Máxima 40 \\
\hline Filtrado $\left(\mathrm{cm}^{3}\right)$ & 14 & 12 & 29 & 15 & Máximo $15 \mathrm{~cm}^{3}$ \\
\hline Análisis de tamizado en húmedo (\%) & 2.30 & 2.70 & 3.80 & 0.70 & 4 \% Máximo \\
\hline Espesor del cake (mm) & 3 & 2 & 1.50 & 3 & -- \\
\hline Humedad Máxima (\%) & 7.90 & 8.90 & & -- & 10 \\
\hline
\end{tabular}

Nota: Las lecturas del viscosímetro, punto de fluencia y el filtrado son medidos sobre una suspensión de 22.5 gramos de bentonita en 350 $\mathrm{ml}$ de agua destilada. (Note: viscometer readings, yield point and the filtrate are measured on a suspension of 22.5 gram of bentonite in $350 \mathrm{ml}$ of distilled water.

Tabla 4. Resultados obtenidos de ensayos reológicos según Normas API, junto con las especificaciones físicas de la bentonita según Normas API 13A-9.1.2.

Table 4. Results obtained from rheological tests along with physical specifications of bentonite in compliance with API 13A-9.1.2 Standards.

la viscosidad. En Tabla 4 se presentan los resultados de la evaluación reológica de las muestras en estudio según normas API. Las bentonitas destinadas para uso en perforaciones deben cumplir los requerimientos especificados según Norma API las cuales se detallan también en Tabla 4.

Para realizar los ensayos de calidad se tienen en cuenta los parámetros más importantes en cuanto a lodos de perforación, entre ellos: la viscosidad, el filtrado y la presencia de residuos. La viscosidad esta relacionada a las propiedades del flujo del lodo, éste debe ser lo suficientemente espeso como para acarrear los ripios hacia la superficie y lo suficientemente delgado como para fluir libremente a través del sistema superficial. El régimen de filtración es una de las propiedades más importantes, ya que es una medida de la cantidad relativa de agua en el lodo perdido en las formaciones permeables y por consiguiente de la cantidad relativa de la costra de lodo depositada sobre las paredes permeables del pozo(Peña, 2007).

$\mathrm{Al}$ analizar los datos reológicos obtenidos de la bentonita $\mathrm{M} 2$, se observa que su viscosidad medida a $600 \mathrm{rpm}$ es mayor a $30 \mathrm{cP}$, su volumen de filtrado es menor a $15 \mathrm{~cm}^{3}$ y también su valor de análisis de tamizado de impurezas es menor al $4 \%$. Esto se ratifica tanto físicamente (alto hinchamiento), como químicamente con que la habilidad de impartir viscosidades altas y desarrollar tixotropía son propiedades sólo de las bentonitas sódicas, en cambio las bentonitas cálcicas generalmente no tienen valores altos de viscosidad o comportamientos tixotrópicos (Kelessidis et al., 2007). Se concluye entonces que M2 es apta para uso en lodo de perforación debido que cumple con los requerimientos establecidos según Norma API RP13A.

\section{E- Ensayos para uso en cerámica:}

En Tabla 5 se detalla por un lado los resultados obtenidos de los ensayos efectuados a las muestras en estudio, y por el otro, comparativamente dato brindado por SEGEMAR de los requerimientos que deben cumplir las bentonitas destinadas para uso en cerámica.

Las arcillas plásticas, dentro de la amplia gama de depósitos existentes, son los de origen sedimentario los que constituyen el mayor volumen y sustentan el flujo de materia prima hacia las principales plantas instaladas en nuestro país. Las arcillas de estos depósitos tienen excelentes cualidades para la denominada cerámica roja. La bentonita no se usa en grandes volúmenes justamente por su plasticidad. Se adiciona para aumentar la resistencia y dar vitrificación apropiada o el color deseado (Herbia, 2007).

De acuerdo con la distribución estructural los minerales arcillosos se pueden dividir en familias o grupos. Dentro de estos grupos, se encuentra la familia de las esmectitas ó minerales expandibles, tal como la montmorillonita, que presentan estructuras que permiten que el agua penetre entre las láminas 
Hidalgo, N., et al., 2016. Caracterización y evaluación de la calidad de bentonitas... Boletín Geológico y Minero, 127 (4): $791-806$

\begin{tabular}{|l|c|c|c|c|c|}
\hline \multirow{2}{*}{ Determinaciones } & \multicolumn{4}{c|}{ Muestras } & \multirow{2}{*}{$\begin{array}{c}\text { Especificaciones físicas de las } \\
\text { Bentonitas } \\
\text { Datos de SEGEMAR }\end{array}$} \\
\cline { 2 - 5 } & M1 & M2 & M3 & M4 & $\leq 15$ \\
\hline Hinchamiento $(\mathrm{ml} / 2 \mathrm{~g})$ & 20 & 40 & 10 & 20 & Máximo 1,6 \\
\hline $\mathrm{Fe}_{2} \mathrm{O}_{3}(\%)$ & 6.58 & 6.74 & 1.30 & 2.90 & Entre $70-75 \%$ \\
\hline Blancura (\%) & 38.30 & 44.0 & 74.70 & 60.20 & No especificado \\
\hline Plasticidad (IP= Índice de plasticidad) & 210.90 & 130.34 & 151.30 & 180.20 & \\
\hline
\end{tabular}

Tabla 5. Resultados de los ensayos realizados a las muestras de bentonitas en estudio, acompañada por las especificaciones de bentonita según datos de SEGEMAR para uso en cerámica.

Table 5. Results of assays performed on the bentonite samples together with bentonite specifications according to SEGEMAR data for use in ceramics.

tetraédricas y octaédricas a través de enlaces de hidrógeno, lo cual determina una expansión de la celda cristalográfica y explica su alto índice de plasticidad. En el proceso cerámico la presencia de minerales de este tipo aún cuando aumentan la plasticidad de la pasta, es un inconveniente porque en el secado los objetos moldeados pierden volumen y se deforman, por eso su uso debe ser cuidadosamente controlado (Bernal et al, 2003). La familia de las micas, si bien siguen el esquema de cristalización de las esmectitas, sus minerales no son expandibles tales como pirofilita y muscovita.

De los resultados obtenidos en Tabla 5 se deduce que la muestra M3 a partir de la caracterización física presenta un hinchamiento menor al $15 \%$, y además a partir de la caracterización química nos indica que se trata de una bentonita cálcica. Ratificando de esta manera que las bentonitas cálcicas se caracterizan por tener bajo hinchamiento y poder de retención de agua. Esta cualidad es particularmente importante para su uso en pastas cerámicas. No así las sódicas que tienen tendencia a fracturarse durante la cocción y el enfriado en la producción de cerámicos (Newman, 1987). Mineralógicamente, la muestra M3, seria apta para uso en cerámica ya que posee el menor contenido en motmorillonita (mineral expandible), a la vez contrarrestándose con contenidos en pirofilita y muscovita que son no expansibles (familia de las micas) por todo lo explicado anteriormente.

La muestra M3 además, presenta bajo contenido en hierro y posee el mayor porcentaje de blancura un $74,3 \%$ y valor de plasticidad no elevados, cumpliendo de esta manera con las especificaciones establecidas en Tabla 5. En resumen, de acuerdo a los ensayos realizados muestran que la bentonita $\mathrm{M} 3$ presenta las propiedades físico-químicas y mineralógicas adecuadas, lo cual posibilita ser utilizada en cerámicas rojas.

\section{Conclusiones}

De las cuatro muestras de bentonitas que fueron caracterizadas tanto física, química y mineralógicamente complementándose con la aplicación de ensayos tecnológicos de evaluación de calidad, se concluye que la muestra M2 proveniente de la provincia de Rio Negro debido a sus características reológicas cumple con las especificaciones según normas API para industria petrolera; y la muestra M3 procedente de la provincia de San Juan debido a sus características físico-químicas y mineralógica (baja reología, hinchamiento, bajo contenido en hierro, entre otros) es apta para uso en cerámica roja según especificaciones dadas por SEGEMAR.

Con respecto a las bentonitas M1 y M4 presentan un hinchamiento apropiado y niveles aceptables de metales pesados que posibilitaría el empleo en otros mercados tales como: nutrición animal y filtración.

\section{Agradecimientos}

A la institución a las que pertenecen los autores y sus respectivas Direcciones de Investigación por el apoyo otorgado para la realización de la presente investigación. A la Lic. María Angélica Mattar, Jefa de área de Mecánica de Rocas, por su inestimable contribución. A la Dra. Ana Mestre por su valiosa sugerencia sobre el manuscrito. Al Msc. Ing. Luis Gutiérrez por su asesoramiento y Guadalupe Gutiérrez ambos perteneciente al Instituto de Investigaciones Mineras.

\section{Referencias}

Arredondo, D. 2009. Resumen de lodos. Informe Inédito, Universidad Autónoma Gabriel Rene Moreno AGRM, Ingeniería Petrolera, Bolivia, 41 págs. 
Behrens, A., Giljum, S., Kovanda, J. and Niza, S. 2007. World wile patterns of natural resourse extraction and their implications for sustainable use policies. Ecological Economics. Elsevier, 64(2) 444-453.

Bernal, I., Cabezas, H., Espitia, C., Mojica, J. and Quintero, J. 2003. Análisis próximo de arcillas para cerámica. Revista de la Academia Colombiana de Ciencias Exactas Físicas y Naturales, 27 (105), 569-578.

British Geological Survey, Brown, T. et al., 2009-2013, World Mineral Production. 22/04/2015, http://www.bgs.ac.uk/ mineralsUK/statistics/worldStatistics.html.

Camacho, J. y Celada, C. 2004. Definición de zonas potenciales para esmectitas en los Departamentos del Valle del Cauca, Tolima y Caldas. Informe Inédito. Ingeominas, Colombia, 25 págs.

Cerámica y Cristal 140, Editorial Ciclo, 23/04/2015, http:/ www.ceramicaycristal.com.ar.

Dias, M., Barrios, M. y Prates, S 2004. Las benotonitas de Benavila (Portugal), caracterización mineralógica y propiedades. Geogaceta, 35(2004), 99-102.

Doval, M., Garcia, E., Luque, J., Martin, J. y Rodas, M. 1991. In: Lunar, R., Oyarzun, R. (ed.), Yacimientos Minerales. Centro de estudios Ramón Arces, Universidad Nacional de Colombia, Colombia, 582-608.

Fundación Okita, 2007. Estudio sobre Cadenas Productivas Seleccionadas en la República Argentina. industria de los minerales no-metalíferos. Informe Inédito. Agencia de Cooperación Internacional del Japón (JICA), Secretaría de Industria Comercio y Minería, Argentina, 118 págs.

Gonzáles, I. 1990. In: García, J and Martinez, J (ed.), Yacimientos Minerales. Recursos Minerales de España, Madrid, 96-112.

Guerstein, P. 1982. Estúdio geológico del Triásico aflorante entre las Quebradas de Hilario y Carrizal. Departamento de Calingasta. San Juan. Trabajo Inédito. Universidad Nacional de San Juan, Argentina, 47 págs.

Grim, R. E., 1962. Applied Clay Mineralogy. Mc Graw Hill, New York, 422 pp.

Grim, R.E. and Guven, N. 1978. Bentonites- Geology, Mineralogy, properties and Uses, Developments in sedimentology. Elsevier, New York, 596 pp.

Hevia, R. 2007. Bentonitas. Propiedades y usos industriales. Informe Inédito. Proyecto INTI- SEGEMAR, Unión Europea, 13 págs.

Iñiguez, et al., 1972. Estudio geológico - económico de los yacimientos de bentonitas del Lago Pellegrini. Trabajo Inédito. Dirección Minería Provincia Rio Negro, Argentina, 25 págs.

Kelessidis, V., Chritidis, G. and Makri, P. 2007. Gelation of water-bentonita suspensions at hight temperatures and rheological control with lignite addition. Applied Clay Science, 36 (2), 221-231.

Laird, D. 2006. Influence of layer charge on swelling of smectites. Applied Clay Science. Elsevier, 34(2006), 74-87.

Lazo, S. y Artica, M. 2006. Activación de la bentonita cálcica por vía ácida y su uso en la decoloración y blanqueo de aceites vegetales comestibles. Trabajo inédito. Facultad de Ingeniería Metalúrgica y de Materiales, Universidad Nacional del Perú, Huancayo, Perú, 112 págs.
Madejová, J. and Komadel, P. 2001. Baseline studies of the clay minerals society source clays: infrared methods. Clays and Clays mineral, 49 (5), 410-432.

Marconi, C. 1998. Bentonitas en Argentina. I Jornada en minerales Industriales. Intemin. Instituto de Geología y Recursos Minerales SEGEMAR. Fundación Empremin, Argentina, 2,123-157.

Molina, M., Moreno, S. y Fernández, J. 2007. Caracterización de las Arcillas Esmectíticas de la Formación Honda al Noreste del Tolima y su Potencial Aplicación como Catalizadores. XI Congreso de Geología, Colombia, 2, 112-121.

Morgan, et al., 1993. Industrial Minerals Laboratory ManualBentonite. British Geological Survey, Mineralogy and Petrography Group, United Kingdom, 10-42 pp.

Newman, A. y Brown, G. 1987. The Chemistry of constituion of clays. In: Newman, A (ed.), Chemistry of clays and clays minerals, London, 1-128.

Odom, I., 1984. Smectite Clay Minerals: Properties and Uses. Phil Trans. R. Soc. London, 391-409 pp.

Odom,I., 1987. Na-Ca Montmorillonita: properties and uses. Society of Mining Engineers of AIME, Pennsylvania, 282:1903-1904.

Patterson, S. and Murray, H., 1983. Clays. Industrial Minerals and Rocks, New York, USA, 519-577.

Peña, J. 2007. Estudio para la Optimización del Uso de Fluidos de Perforación en el Campo de Petroproducción. Trabajo Inédito. Facultad de Ciencias de la Ingeniería Escuela de Tecnología en Petróleo Equinoccial, Quito, 156 págs.+10 págs. (anexos).

Ross, C. S. and Shannon, E. U., 1926. The minerals of bentonite and related clays and their physical properties. American Ceramic Society Journal, 77-96.

Roskill, 1997. The economics of bentonite. Information 8th Edition, London, $125 \mathrm{pp}$.

Schalamuk, I.B y Cábaña, M ,1999. Bentonitas de la región precordillera de San Juan y Mendoza. Recursos Minerales de la República Argentina (Ed. E.O. Zappettini). Instituto de Geología y Recursos Minerales SEGEMAR, 35: 921-927

Teague, K.H., 1972. Southern Bentonite. SME (Society of Mining Engineers). AIME. American Institute of Mining Metallurgical and Petroleum Engineers, Pennsylvania, $72 \mathrm{H}, 328$.

UNSAM. 2007. Información económica de bentonita. Informe Inédito, Publicación técnica, Argentina. 87 págs.

U.S. Geological Survey, 2015, Mineral commodity summaries: U.S. Geological Survey, 22/04/2015, http://minerals.usgs.gov/minerals/pubs/mcs/2015/mcs2015.pdf

Valles, M. y Impiccini, A., 1999. Bentonitas de la Cuenca Neuquina Río Negro, Neuquén y la Pampa. Recursos Minerales de la República Argentina (Ed. E.O. Zapettini, Instituto de Geología y Recursos Minerales SEGEMAR) 35: 1113-1125.

Vega, F., Verdeja, L., Sancho, J. y García, J. 1993. Caracterización y propiedades de las bentonitas de Amapote. Boletín Sociedad. Española Cerámica y Vidrio, 32 (6), 377-383. 
Viruel, M.E. y Lombardero, M., 1998. Los minerales industriales y las rocas de aplicación en la Quebrada de Humauaca. Estudio Geológico Integrado de la Quebrada de Humahuaca. Anuales XXX. SEGEMAR, $5(3), 32-35$.
Wetten, F. y Baraldo, J., 1984. Geología de los yacimientos de bentonitas existentes entre las localidades de Colón y Quebrada Carrizalito, Dto de Calingasta, San Juan. Instituto de Investigaciones Geológicas, Universidad Nacional de San Juan, 5(3), 12-14.

Recibido: febrero 2016

Revisado: mayor 2016

Aceptado: julio 2016

Publicado: diciembre 2016 